\title{
Intelligent urban environments: towards e-inclusion of the disabled and the aged in the design of a sustainable city of the future. A South African example
}

\author{
E. V. Macagnano \\ Meraka Institute (African Advanced Institute for ICT), Council for \\ Scientific and Industrial Research - CSIR, Pretoria, South Africa
}

\begin{abstract}
City sustainability can only be achieved through full integration of all its citizens in city life, in particular the aged and people with disabilities. Why? In every modern society they represent up to $20 \%$ of the population. Their number is now increasing due to medical advances, causing an increasing economic burden on society. Yet they have the right to dignity, socio-economic opportunities, inclusion and participation to socio economic development and opportunities. An extended working life and independent access to city resources would reduce such problems.

This Paper describes comprehensive research undertaken in Pretoria, South Africa proposing substantial changes to commonly accepted city environments (in relation to urban design, infrastructure provision and utilization of services) into 'Intelligent Enabling Environments', where disabled and aged people would be provided with user-friendly wearable computing devices, connected to a wireless, distributed and invisible two/multi-way data transmission system, able to allow access 'on-the-go' of useful data related to buildings, urban infrastructure and services, and to transmit also user's personal data. Data would include information on public buildings (location, accessibility, services provided), events, accessible city routes, info on public transport and relevant navigational data. Users would be automatically $3 \mathrm{D}$ tracked and the display of information would be' hands-free' and embedded in flexible wearable devices in personal clothing, or as part of miniaturized head-mounted-devices, customized to provide also audible information in multiple languages. Information would be accessed through interactive menus, designed around users' life-styles, activities, education and valid both in a first and a third-world urban design context; it would be transmitted and received within enabled 'smart buildings' and also through an urban wireless system, via satellite and/or hot-spots. The design of future cities would be affected, revolutionized and made more effective, therefore sustainable. This paper explores the research methodology followed and the results obtained. The project has embraced current research on innovative futuristic technologies and focuses on a 'Technology Demonstrator' executed in a city block in the city of Pretoria.
\end{abstract}




\section{Introduction}

It is estimated that, in South Africa, by 2015 approximately $75 \%$ of the population will be residing in metropolitan/urban areas. Among the current population it is also estimated that people with disabilities and the elderly, collectively comprise approximately $20 \%$ of the population (currently 8 million people) and are in great need of social and economic upliftment and integration in society.

In this respect, significant research challenges still remain, before true independent living within a totally barrier-free 'enabled' environment, both at home and within the outside world, can be achieved

In the 'first' world, in recent years, an array of assistive devices have been conceived and manufactured on an on-going basis, specifically designed to offer independent and meaningful living to people with disabilities (physical and mental) and to the aged.

Because of this effort, in the developed world some disabled and aged people can now live reasonably independently, longer and at a lower cost of care to their societies.

Comprehensive design codes of practice and legislation have also been developed, giving guidance on what should be done to offer independent living and opportunities to contribute fully to society.

Modern buildings and many cities around the world are now equipped with accessible, barrier-free infrastructure, components and equipment in an array of different shapes, sizes and technical details/innovation, to allow people in need to operate efficiently and independently in most circumstances.

However, most of the solutions offered, although significant, are of a purely 'physical' nature (ramps, grab-bars, wider doors, lifts, handles and switches, textured footpaths, hydraulic lifts to trains and buses, vibrating plates at traffic lights, audio warnings etc.) therefore of rather limited scope and with very little intelligence (Figure 1).

In recent times however, some technology research has been initiated to develop Information and Communication Technologies (ICT) to build intelligence into a future 'smart city environment' where buildings, public and private transport and physical infrastructure in general are made more accessible and safe through the integration of ICT. The Meraka Institute at the CSIR in Pretoria, South Africa has been conducting research along those lines: this ongoing multidisciplinary research is expected to have far reaching benefits beyond the original driving forces, improving the quality of life in all urban areas for the benefit of all city users and residents. This Project results from currents trends in scientific disciplines such as Human Computer Interaction, Ergonomics, Wireless tracking, Industrial Design, Intelligent buildings, Wearable Computing, Nanotechnology etc, and proposes inter alia the building of skills, the activation of research streams, the establishment of a network of excellence in alignment with them in order to guarantee city sustainability for the future. It proposes also ICT refurbishment and equipping of current SA cities and a different approach to Urban Design of the city of the future, in terms of alternative concept-design of 


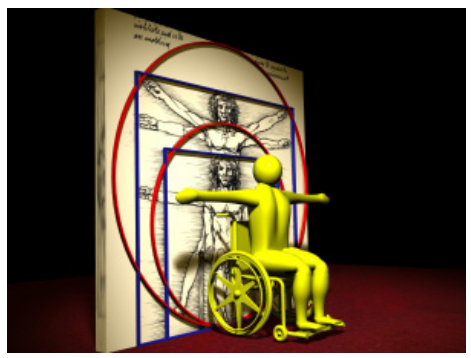

Figure 1: $\quad$ Able to disabled: a challenge for all.

buildings, ICT based infrastructure provisions, socio-economic integration of all city dwellers and ultimately City Sustainability.

\section{What is an Enabling Environment?}

Imagine a world where an elderly, partially disabled person carries with him/her a 'smart device' connected to an integrated digital network capable of offering total, interactive connectivity, inside his/her home, around the neighborhood and a city level.

What would such system do? Some practical examples:

- Inside the home:

- Automatically sending of alerts to the resident re: approaching visitors/intruders (safety issue), water leaks, open windows etc.

- $\quad$ Resident tracking (3D, on all floors) through embedded sensors capable to pinpoint/track where a resident is at all times (security issue).

- Total remote management of home devices (fridge, taps, stove, windows, air-conditioning), (convenience, health).

- Remote diagnostics of the individual physical conditions (heart-rate, perspiration, rate of breathing, state of comfort.) and remote adjustments (pace-maker, hearing devices etc.) (Figure 2).

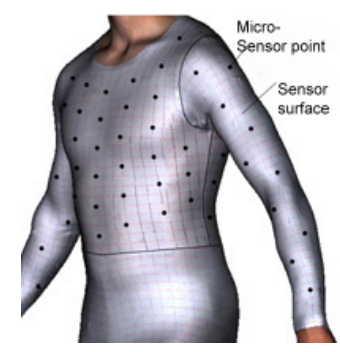

Figure 2. 
- Alerting far-away family and care-givers of unusual inactivity (fainting, falling etc.) (safety).

- Automatic indoor climate adjustment according to the time of the day, season, outside humidity, type/density of clothing etc. (smart-home).

- Wearable computer (material/cloth as 'display' on demand and micro wearable low-power processor (Nano-technology devices) and so on (Figure 3).

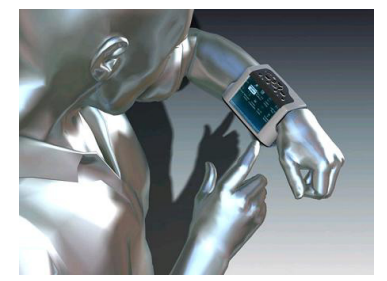

Figure 3.

- Outside, in the city environment:

- 3D GPS-based (satellite) movement tracking of elderly/disabled, with automatic recording of sequence of movements, places visited, date, time of day, time-line sequences of actions and events, giving necessary alerts to care-givers and family (unwanted 'wandering', accidents..), (safety issue).

- Fixed city 'hot-spots' (mounted on buildings) not only allowing longrange wireless connectivity but also capable of real-time tracking of people position and movements, in complex 3D environments (shopping centers, hospitals) with the capability to 'make sense of it all', correlate information and relay it automatically to caregivers/family according to pre-set intelligent criteria. (Figure 4).

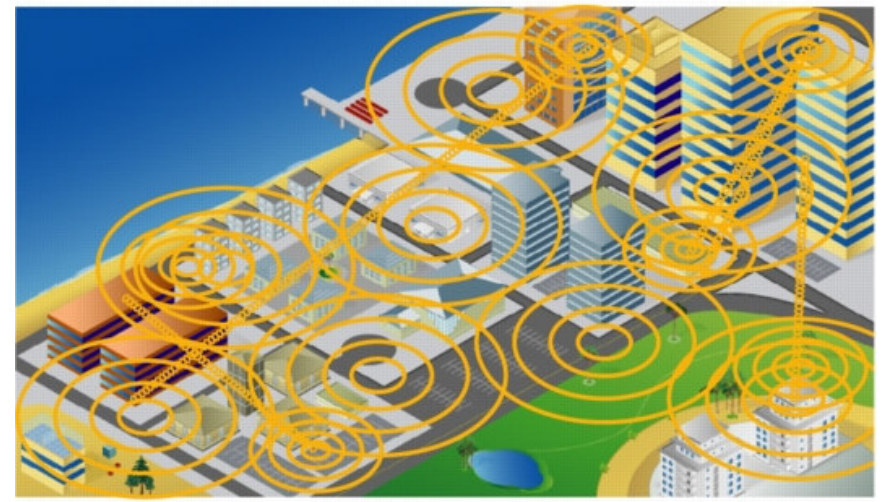

Figure 4. 
- Intelligent video-tracking (CCV) in the city, capable of recognizing a danger situation from 'body language' and/or unusual behavior (fainting, epilepsy fit, heart-attack etc.) and to summon help (at a bus stop, train station, airport etc.).

- Provision of 'Augmented-Reality' miniaturized head-mounted, nonintrusive, devices, (foldable High-Resolution and transparent mini-screens superimposed on common viewing glasses or independently fixed to head or ear), (Figure 5), capable of displaying to the bearer (through Augmented Reality technology), at will, information on surrounding environments, graphically superimposed on-to the visible environment (telling the wearer where to turn to find a specific shop, an accessible ramp into a building, in what direction to walk to the clinic or doctor, which bus to take, bus time tables at the bus stop etc..). All this by simply 'looking at' buildings, bus stops, streets, and 'seeing' data superimposed on to it (Figure 6).

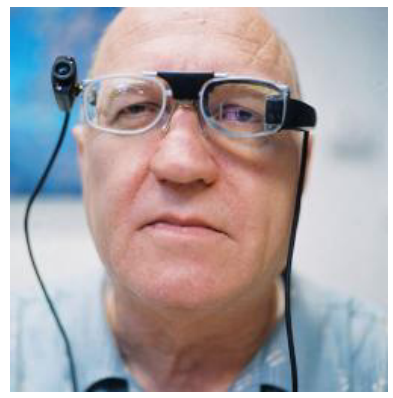

Figure 5 .

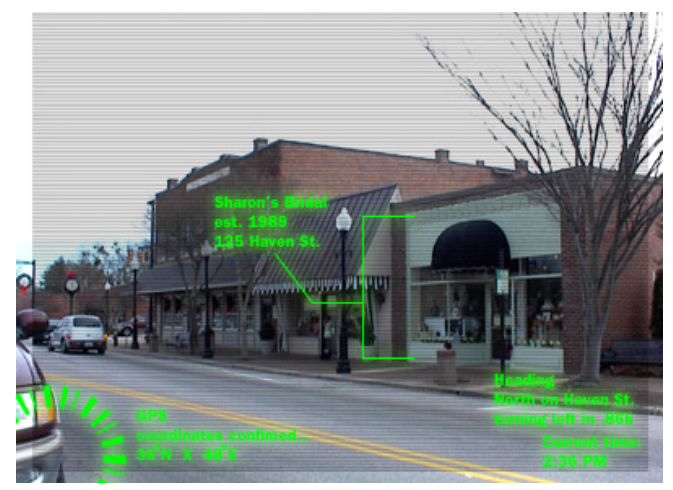

Figure 6: Augmented reality representation.

- The disabled/elderly person is simply tracked in real-time by GPS/hot-spot and pinpointed 3Dimensionally within the city. This allows the System to 'reset" and calibrate accordingly. All sorts of information is then automatically relayed/offered, in real-time and according to pre-set 
requirements. The disabled/elderly has only to synchronize onto a chosen menu (transport, shopping, health care, entertainment) and the surrounding environment becomes 'really' barrier-free, by offering visual/audio appropriate information.

- In this context, audible messages (blue-tooth, WI-FI and next generation wireless technologies) could also verbally describe to the user (blind), in real time, what is happening (next bus stop name, name of shop owner, timetables etc.) according to his/her 3D position in the city.

\section{Where should these enabling and interactive technologies be provided?}

- In private and public buildings: libraries, municipal offices, places of learning, police stations, churches etc.

- On the streets, along pavements and in public open spaces.

- On public transport (rail stations, bus stops, airports etc.).

- In public parks, restaurants, recreational facilities etc.

- Access would be totally voluntary (possible exceptions in health specific cases needing constant supervision).

The pre-setting to be done by experts, also involved in settings modifications according to circumstances and on demand.

\section{South Africa as testing ground}

The research project's intention was to benefit from international research but also to go one step forward towards the creation of an enabling intelligent environment, designed around the harsh realities of a 'developing world': in this respect South Africa cities demonstrated to be an ideal testing bed, accommodating first and third worlds, operating simultaneously and in a complementary fashion.

Through the use of 'assistive' technologies, coupled with networking and communication protocols, the aim of this project was ultimately to establish a platform of knowledge, a network of excellence and a basis for applied research, specially crafted and appropriate for the benefit of South African disabled and aged people in the city of the future.

\section{Project methodology and main executed tasks}

The main project objectives were assembled into do-able and well defined executive workable tasks, allocated in different configurations to members of the Meraka team in various assemblages and configurations.

The identified working tasks were as follows:

- Establish a 'technological bench-mark': examine and document the international status quo, major existing and under development technologies and current relevant research (intelligent buildings, automatic video tracking, wearable computing, augmented reality etc.). 
- Work towards a 'network of excellence' among scientists currently engaged, internationally in ICT based barrier-free environmental research and solutions development (built environment).

- Create an international 'virtual laboratory' for sharing of info/data among chosen scientists.

- Select one 'real' environment to do research on selected willing individuals, at city level Centre of Pretoria). (Figures 7 and 8).

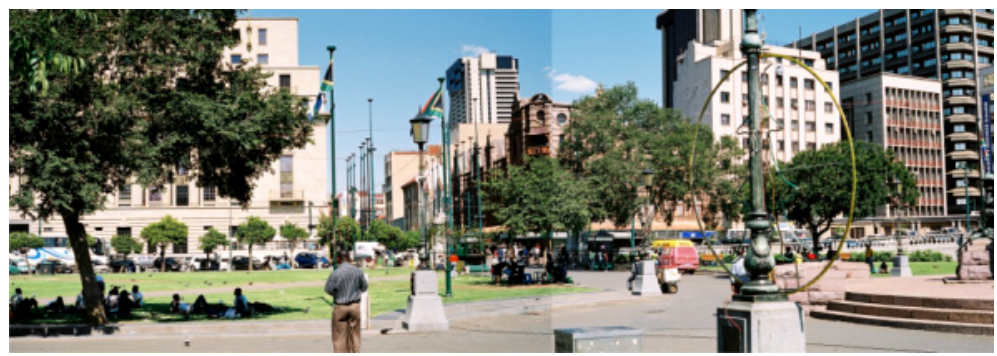

Figure 7: Church Square, Pretoria.

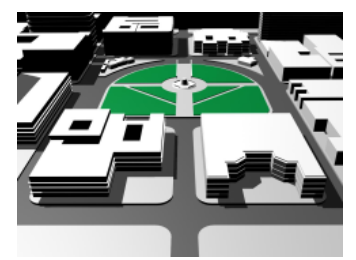

Figure 8: $\quad 3 \mathrm{D}$ modelling.

- Carry out research and prototyping towards the future establishment of a wireless intelligent network capable of tracking subjects' 3Dimensionally also in a busy/complex spatial environment.

- Develop a long-term technology strategy/road-map to work towards the visions of the project.

- Create a SA critical mass of excellence at the forefront of international R\&D and initiate international exchanges.

- Hold workshops involving young researchers and upcoming ICT young entrepreneurs (BEEs etc.) in previously disadvantaged population groups.

- Initiate collaboration with SA-ICT industry and academia.

- Explore the potential of current incubators in taking up some of the new opportunities in Enabling Environments (EE), and explore sustainability issues and growth of local ICT industry.

\section{Problems and challenges encountered in the definition and execution of tasks - the issue of team building}

The Project team was a multidisciplinary one, being made up by researchers from three very different CSIR Strategic Units, such as: 
- The Meraka Institute, comprising ICT experts in the following capabilities: wireless technology, computing technology, barrier-free technologies for the disabled and the aged. This entailed the capability to provide solutions towards ICT enabling systems at building/city levels.

- The Built Environment Unit, comprising expertise in intelligent and sustainable buildings, town planning, transport and urban design. The focus was on ICT integration to city planning and design.

- The Industrial Design and Engineering Unit, which provided expertise in $\mathrm{CAD} / \mathrm{CAM}$ production and manufacturing systems and strategies. This was used towards Design and prototyping for wearable computing and assistive devices.

The overall team was therefore made up by researchers operating in and coming from a variety of disciplines and backgrounds, complementary to each other and using a common platform of understanding and a common language. The benefits from such diversity were apparent from the beginning, offering lateral thinking and unexplored avenues to the research streams and activities. In addition other disciplines were added during the execution of the project, such as Social Sciences expertise, capable to address the issue of cultural diversity within the context of South African society and also within a city context.

\section{Project execution: major themes, activities and research results}

\subsection{Critical evaluation of results}

The team focused on 5 specific research areas which were: Universal Design; Human Computer Interaction; Computational issues in Ambient Intelligence; Intelligent Awareness and Vision based interaction.

It became soon evident that the 'information society' has moved away from Desktop Computing to Mobile/Wearable computing and is now moving towards the notion of Ambient Intelligent Computing. The main characteristics of Ambient Computing is that it is ubiquitous, yet unobtrusive, with technology becoming more and more embedded in everyday objects and playing a major part in all people's lives.

Applications, services and systems are becoming available everywhere, integrated with each other and with multiple devices, environments and people, and present in every physical/virtual context of a human user. The user will in essence be unaware of the technology and only concentrate on completing his/her task, with the technology automatically and intelligently adapting to the needs and requirements to assist the user in whichever manner the user prefers.

This shift is clearly evident in the current global focus on wireless connectivity, embedded computing, nanotechnology, computational intelligence and smart homes. 


\subsection{Ambience Intelligence: new technical definitions and ethical issues}

An Ambient Intelligent Environment was defined as comprising of diverse services, systems and applications and being able to efficiently integrate, manage and execute these varying computational sources. Ambient Environments have specific computational properties that distinguish them from other computational systems, such as:

- They have large numbers of hardware and software components.

- The components must be interconnected and operate in real-time.

- The infrastructure is highly distributed.

- They need large amounts of computational power.

- They are highly dynamic and need reconfiguration and resource management on the fly.

- They have multi-modal interfaces and high degrees of parallelism for resolving multiple, simultaneous events.

- They can be ubiquitous (not visible) and embedded in the city fabric.

In this new 'ambient enabled environment' the 'users' become the primary focus and their needs and abilities (or lack of) must be taken into account throughout the design and development process. The creation of Enabling Environments (EE) can only be possible if the technologies that are put in place take into account usability and accessibility issues.

In order to have in place systems capable to anticipate the user's needs and automatically 'adapt' to the users, they must become "multi-modal" adaptive systems allowing complete interactivity in any preferred way.

The 'ethical' issues of ever-present, fully automated and potentially intrusive technologies need to be considered. Questions like the amount of control that a user is willing to concede to an automatic environment, as well as the health and safety concerns that this will raise, is a vital part of the development of the technology, within the design of the city of the future.

\subsection{The technology demonstrator}

Following international R\&D surveys, the establishment of $R \& D$ partnerships and networks, and after evaluation of the unique South African city context, various case studies were designed (using real people and typical city events) around various disabilities and in variety of socio-economic scenarios, aimed at the creation of technological solutions appropriate for SA people/cities and capable of generating spin-off ideas suitable for subsequent R\&D. To that effect, the Pretoria Church Square was chosen as the testing ground, where subjects would be chosen, where questionnaires would be implemented, where devices would be embedded in the city fabric and on transport systems and where the overall effects and benefits could be examined and analyzed in detail.

A 'technology demonstrator was then designed and publicized/translated into a comprehensive video in DVD format, for public distribution.

Some of the suggested technologies include adjustable ramps/counters capable to intelligently adapt to an automatically detected user; mobile devices connected to local wireless networks and capable to assist in navigation and 
transmitting user's personal data in case of emergency; a 'sign language communication booth' with automatic video conferencing and image processing capabilities for the deaf etc.

The above research was included in a CSIR comprehensive technical report, listing in detail current research, trends and applications and future trends.

\section{Recommendations: an intelligent sustainable city for the future}

The strive to achieve a truly 'sustainable' future city must focus on five main research themes to be addressed by all involved in such a process:

- "Humanity". This theme speaks to the social, human and cultural aspects of the research and includes social engineering, human computer interaction soft issues, disability research and implementation in a developing world context.

- "Awareness". This involves technologies that sense/perceive objects/persons within the environment, in order to collect information about the state of the environment and its users. Amongst them: context awareness, user profiling and active sensor technology.

- "Intelligence". This provides location-based intelligent context, reasoning and interaction, allowing the environment to reason about the current state and determine appropriate actions. These include intelligent information management, machine reasoning and world modeling.

- "Physical Enablers". These are devices, technology and hardware through which the users interact with the environment and which facilitate an intelligent environment. Examples are assistive technologies, within a universal design in the built environment and middleware.

- "Software Engineering". This deals with the computational methods/applications required for an Intelligent Environment such as software methodologies and processes, quality engineering, architectures, platforms and universal design in applications.

\section{Specific South African challenges}

There are a couple of reasons that differentiate this project from ongoing research in this field. Firstly, the focus was on the total array of disabilities and not just on selected ones. Secondly the research takes into consideration the developing world context, as well as the multi-cultural environment of South Africa. This means that any research will have to be cognizant of challenges such like limited telecommunications coverage, limited access to ICT and electricity, as well as the differing context profiles of users with different language, education and cultural needs. The multi-disciplinary combination of competency in design, architecture, development and the built environment has given the EE team a unique perspective on the research domain which may not have been possible in a more traditional team composition. 


\section{Conclusion}

New urban assessment procedures and rapid intervention methodologies, in response to the challenges in SA (and in the developing world) Metropolitan areas, demand innovation and forward thinking.

Architects, Urban planners, Engineers and Urban Designers must exit their 'comfort zones' and embrace new technologies currently being developed.

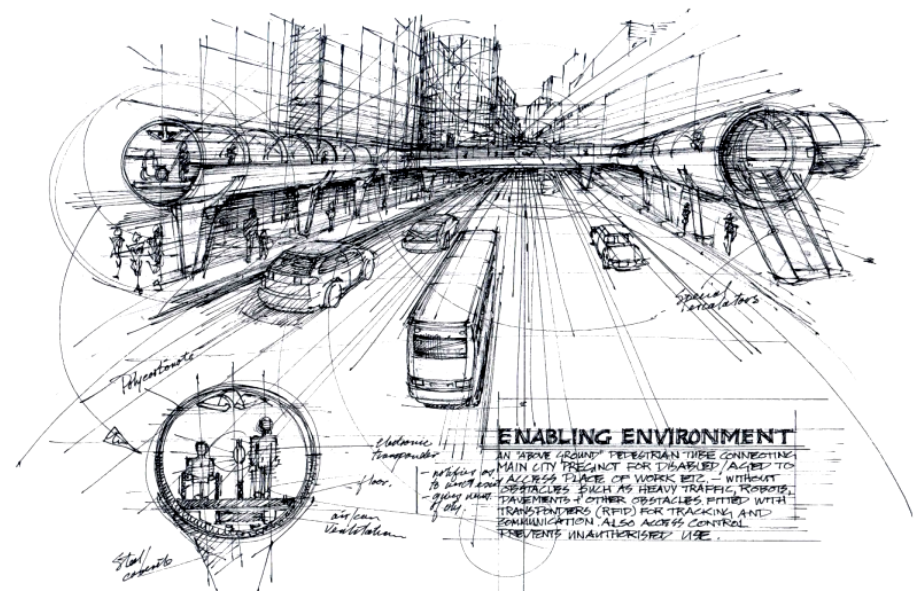

Figure 9: The integrated, accessible city of the future.

ICT and related disciplines can offer the insertion of 'intelligence' into an urban context, both in a developing and developed context.

The Design of the city of the future must integrate such technologies.

This new context, where all disciplines are fused together with advanced technologies, will create an integrated environment where the growing number of the 'disadvantaged' will be totally integrated (Figure 9).

The result will be a better city for all, dynamically used to its full potential, capable to protect and serve its citizens and ultimately 'sustainable'.

\section{References}

[1] The Reconstruction and Development Programme: a policy frameworkAfrican National Congress- Umanyano Publications - Johannesburg, South Africa- 1994.

[2] Environment and Urbanisation - Volume 6, No. 1 - IIED London, UK Diana Miltlin, Managing Editor - April 1994.

[3] White paper on an Integrated national disability Strategy - Office of the Deputy President T.M.mbeki- South African Government - November 1997 